\title{
Onychomycosis in Ceará (Northeast Brazil): epidemiological and laboratory aspects
}

\author{
RSN Brilhante/*/*****, RA Cordeiro*/***/+ , DJA Medrano*, MFG Rocha/*, \\ AJ Monteiro****, CSP Cavalcante, TEF Meireles*/**/***, JJC Sidrim*/***
}

\begin{abstract}
Faculdade de Veterinária, Pós-graduação em Ciências Veterinárias *Centro Especializado em Micologia Médica, Faculdade de Medicina, Departamento de Patologia e Medicina Legal ****Departamento de Estatística e Matemática Aplicada, Universidade Federal do Ceará Rua Monsenhor Furtado, s/n, 60430-350, Fortaleza, CE, Brasil **Centro de Dermatologia Dona Libânia, Fortaleza, CE, Brasil ***Departamento de Biologia, Universidade Estadual do Ceará, Fortaleza, CE, Brasil
\end{abstract}

Knowledge of epidemiological and mycological characteristics of onychomycosis has been noted by many authors as being an important tool for control of these fungal infections. This study seeks to improve knowledge of onychomycosis epidemiology and mycological features. Samples were taken from infected fingernails and toenails of 976 patients undergoing treatment at a respected Dermatology Center in Ceará, Fortaleza, CE, Brazil. Specimens from 512 patients (52\%) were positive for onychomycosis. From the culture-positive samples, yeasts of the genus Candida (C. albicans, C. tropicalis, C. krusei, C. parapsilosis) were dominant. The dermatophytes isolated (Trichophyton rubrum, T. tonsurans, T. mentagrophytes var. mentagrophytes) were dominant in 46 patients (12.99\%). The mould Fusarium spp. was isolated from 29 patients (8.19\%). Yeast of the genus Candida is the main causal factor in onychomycosis in our region. Also, the study showed the importance of performing direct examination and culture in diagnosis of onychomycosis.

Key words: onychomycosis - epidemiology - Candida spp. - Brazil

Onychomycosis is a denomination used to describe nail infection usually caused by dermatophytes, yeast, and non-dermatophytic moulds (Mercantini et al. 1996, Weitzman \& Summerbell 1996). These fungi may cause onychomycosis particularly as secondary invaders after damage by trauma or disease (Haneke 1991, Elewski 1998).

Onychomycosis affects approximately $5 \%$ of the population worldwide (Murray \& Dawber 2002) and represents around 30\% of all superficial mycotic infection (Migdley et al. 1994) and 50\% of nail disorders (Drake et al. 1996, Ghannoum et al. 2000).

Dermatophytes are responsible for nearly $90 \%$ of toenail onychomycosis and at least $50 \%$ of fingernail infections (Elewski 1998). Candida species, particularly $C$. albicans, prevail in fingernail infections (Lopes et al. 1999, Pontes et al. 2002). Non-dermatophytic moulds are rare, but a number of species, such as Fusarim spp., Scytalidium spp., and Acremonium spp. have also been described as etiological agents of onychomycosis (Migdley et al. 1994, Tosti et al. 2000, Pontes et al. 2002).

The epidemiology of onychomycosis has been well studied in some countries, but few data are available in tropical countries (Kam et al. 1997). In addition, research on this theme is poorly exploited in Northeast Brazil. This study, therefore, seeks to improve knowledge of the epidemiology and the mycological features of onychomycosis.

+Corresponding author. E-mail: ross@uece.br.

Received 16 November 2004

Accepted 16 March 2005

\section{MATERIALS AND METHODS}

Patients - Over a period of three years and nine months (March 1999 - December 2002), clinical specimens from 976 patients suspected of onychomycosis were examined in a Specialized Medical Mycology Center of the Federal University of Ceará, Fortaleza, Brazil. The samples were obtained from a renowned Dermatology Center. The clinical and laboratory data were recorded in an appropriate file.

Specimen collection and processing - The specimens were obtained from clinically abnormal nails, by a vigorous scraping of the nail bed, the underside of the nail plate and the hyponychyum, after cleaning the affected areas with $80 \%$ ethanol. The samples of each patient were placed in separate sterile Petri dish and transported to Medical Mycology Specialized Center. Scales scraped from the nails were analyzed for fungal elements, such as hyphae or blastoconidia, by direct microscopy examination, in potassium hydroxide (30\%). For fungal cultures, all samples were inoculated on each of three isolation media (i) Sabouraud glucose agar (SGA; Difco Laboratories, Detroit, MI), (ii) SGA with 5\% chloramphenicol, and (iii) Mycosel agar (Sanofi, France). The culture tubes were incubated at $28^{\circ} \mathrm{C}$ and examined daily for one month. Specimens from the lesions were repeatedly collected three times when it was observed growth of a nondermatophyte alone from a specimen that has tested positive for fungi on direct microscopy.

Strain identification - The yeast isolates were identified according to morphological characteristics and the biochemical profile. To determine yeast micromorphology, cornmeal-Tween 80 agar plates were streaked and stabbed with a 48-h-old yeast colony, covered with a sterile cover- 
slip, incubated at room temperature for 3 to 5 days in the dark to promote the production of chlamydospores, hyphae, pseudohypha, and arthroconidia. Biochemical tests were performed by assimilation method on yeast nitrogen base (Difco) containing 2\% agar, using disks impregnated with various carbohydrate sources. Noticeable growth around the disks after 47 days of incubation at $28^{\circ} \mathrm{C}$ indicated assimilation of the respective carbohydrate sources. Fermentation of sugars was performed by inoculating 0.1$\mathrm{ml}$ quantities of 48-h culture suspensions of test isolates into tubes of fermentation broth containing $2 \%$ solutions of the respective sugars. A positive result was indicated by production of acid and gas. Fermentation and assimilation tests were performed as suggested by Sandven (1990). Dermatophyte identification was based on micromorphological aspects on slide culture in agar potato block. In addition, the identification was confirmed by hair perforation test in vitro, test on the positive urease and by analysis of vitamin requirement. The identification of nondermatophyte fungi species was performed by following micro and macroscopic evaluations of the primary cultures and slide culture in agar potato block, according to De Hoog et al. (2000).

Statistical analysis - The study was conducted utilizing descriptive variable analysis. The Fisher test was used for the analysis associations of the categorized variables in percentages. The ANOVA and T-student were used for analysis associations of ages.

\section{RESULTS}

From 976 patients with clinical lesions in the nails, 512 (52\%) had onychomycosis. Direct microscopic analysis was positive in $468(47.95 \%)$ specimens. Clinical specimens from 158 patients were positive in microscopic examination, but had negative culture. In addition, fungal positive cultures were observed in 354 specimens, of which 310 and 44 , respectively, were positive and negative in the direct examination (Table I).

Regarding gender, 121 patients (24\%) with onychomycosis were males and 391 (76\%) were females. Patients with age varying from 40 to 59 years old were more af-
TABLE I

Results of values of positive and negative direct microscopic examinations versus positive and negative cultures

\begin{tabular}{lccc}
\hline & \multicolumn{3}{c}{ Culture } \\
\cline { 2 - 4 } $\begin{array}{l}\text { Direct } \\
\text { examination }\end{array}$ & Positive (\%) & Negative $(\%)$ & Total $(\%)$ \\
\hline Positive & $310(31.76)$ & $158(16.19)$ & $468(47.95)$ \\
Negative & $44(4.51)$ & $464(47.54)$ & $508(52.05)$ \\
\hline Total & $354(36.27)$ & $622(63.73)$ & $976(100)$ \\
\hline
\end{tabular}

fected and represent $41 \%$ of the positive results. The age groups least affected were from 0 to 9 years $(2 \%) ; 10$ to 19 years $(6 \%), 70$ to 79 years $(8 \%)$; and $>80$ years $(2 \%)$ (Fig. 1).

Fingernails were the most frequent anatomic site in 385 patients $(75.2 \%)$ and toenail onychomycosis was confirmed in 111 patients $(21.68 \%)$. In addition, 16 patients $(3.12 \%)$ presented infections on fingernails and toenails simultaneously. The predominance of lesions in fingernails were higher $(\mathrm{p}=0.022)$ in women $(77.75 \%)$ than in men $(66.94 \%)$. However, toenails were more affected $(\mathrm{p}=$ $0.016)$ in men $(29.75 \%)$ than in women $(19.18 \%)$, as illustrated in Fig. 2.

With regard to the positivity of the direct exam and culture, of a total of 512 patients that tested positive for onychomycosis, $310(31.76 \%)$ were positive in both exams, $158(16.19 \%)$ were positive in only the direct exam, and $44(4.51 \%)$ patients were positive only for culture (Table I).

The etiological agent most frequently found in cases of onychomycosis was C. albicans with a total of 108 patients (30.51\%), followed by $C$. tropicalis $(\mathrm{n}=80 ; 22.6 \%$ ) and $C$. parapsilosis $(\mathrm{n}=78 ; 22.03 \%)$. Of the dermatophytic fungi, Trichophyton rubrum was the most involved, being responsible for 32 samples $(9.04 \%)$. Other dermatophytic strains were identified, with $T$. tonsurans and $T$. mentagrophytes var. mentagrophytes responsible for 2.54 and $1.41 \%$ of cases of onychomycosis, respectively. Regarding filamentous, non-dermatophytic fungi, Fusarium

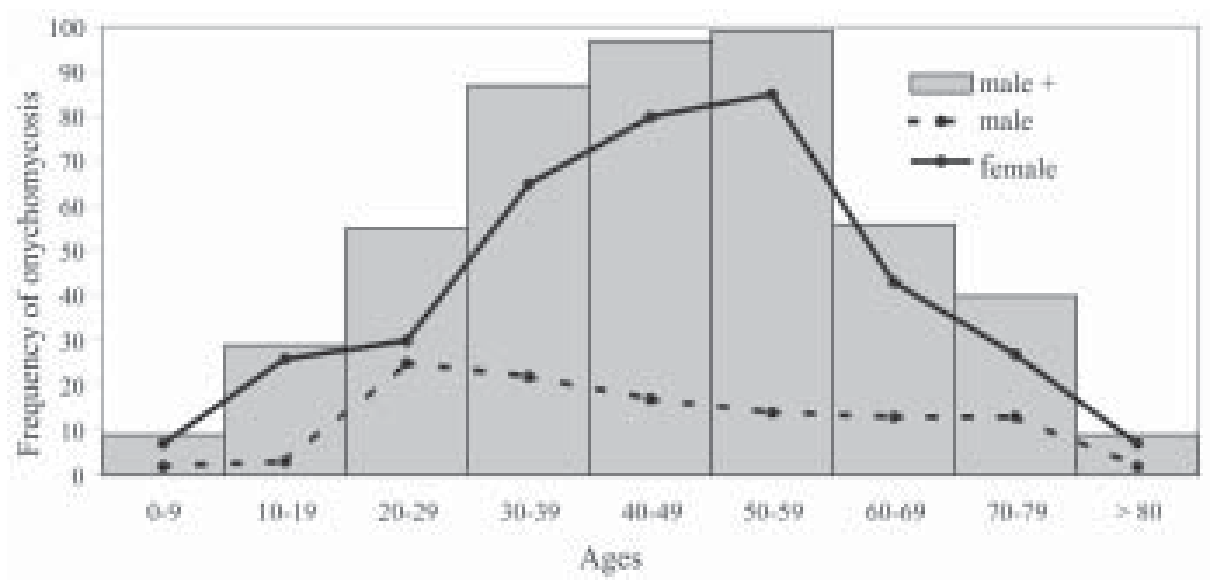

Fig. 1: prevalence of onychomycosis in 512 patients according to sex and age relationship. 


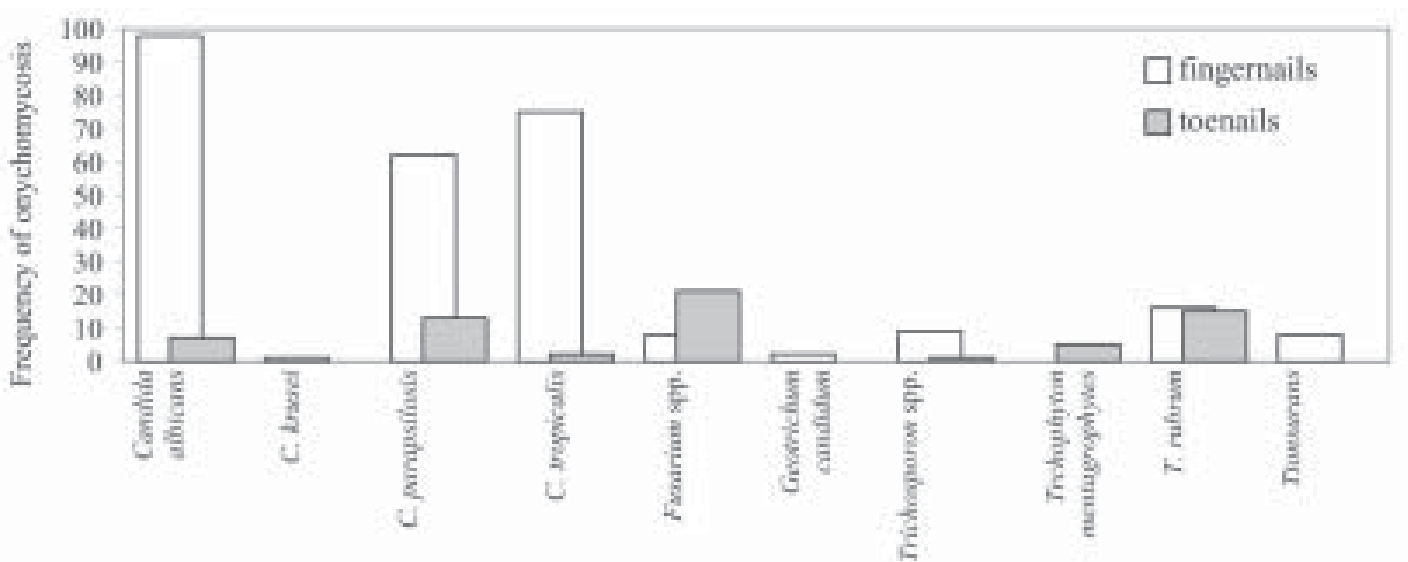

Fig. 2: percentage of onychomychosis in 512 patients according to sex and anatomic site.

spp. was the most frequently isolated, being responsible for $8.19 \%$ of cases. Geotrichum candidum was isolated in only two specimens, corresponding to $0.56 \%$ of cases of onychomycosis (Table II).

In the cases of fungi of the genus Candida spp., females were most susceptible, representing $65 \%$ of cases analyzed. In Fusarium infections, it is possible to note a predilection for the female gender, having been affected in $68.97 \%$ of the data analyzed. In relation to other fungi, there was no gender-specific preference (Fig. 3).

\section{DISCUSSION}

Onychomycosis is a chronic infection of the nails, nowadays considered a serious problem for public health, in view of its high occurrence in the world-wide population (Elewski 1998). This prevalence is probably even higher than is currently thought, as the difficulty in clinical-mycological diagnosis, inappropriate collection of material for analysis as well as ineffective treatment make it hard to ascertain the true profile of such onychopathies.

In this study, the prevalence of onychomycosis was confirmed in $52 \%$ of patients analyzed, these data exceeding those published in Madrid, Ontario, Northern Greece, Italy and Turkey, at 2.8, 6.86, 20, 26.3, and 41\% respectively (Mercantini et al. 1996, Gupta et al. 1997a, Kiraz et al. 1999, Perea et al. 2000, Koussidou et al. 2002).

However, the results of this research demonstrated values near to those found by Lopes et al. (1999), in a 10year retrospective study in the South of Brazil, which showed positivity of $56.6 \%$ through culture. On the other hand, Pontes et al. (2002), in the city of João Pessoa, Northeast Brazil, observed greater prevalence of onychomycosis, with $66.5 \%$ positive cultures.

Fungal nail infections increase with age (Mercantini et al. 1996, Kam et al. 1997, Dogra et al. 2002), the average age of the population of positive patients analyzed in this study was 45.34 years. Within the female group, $62.16 \%$ of patients were between 30 and 59 years of age. Only $47.75 \%$ of men, however, were affected between the ages of 30 and 59. The increase in cases with age may be justified by repeated nail micro-trauma, due to a more prolonged exposure to pathogenic fungi (Drake et al. 1996, Elewski \& Charif 1997); as well as greater work activity and venous insufficency. During the study, a total of 31 patients failed to inform age, however, in view of this small number, there was no negative impact upon analysis.

With regard to children, during the study it was noted that $5 \%$ of then were individuals between 0 and 14 years of age, the predominant gender being female. According to Fernandes et al. (2001), during a study with 137 chil-

TABLE II

Frequency of onychomychosis according to the etiologic agent and the anatomic site

\begin{tabular}{|c|c|c|c|c|c|c|c|c|}
\hline \multirow[t]{2}{*}{ Anatomic site versus culture } & \multicolumn{2}{|c|}{ Fingernails } & \multicolumn{2}{|c|}{ Toenails } & \multicolumn{2}{|c|}{ Fingernails and toenails } & \multicolumn{2}{|c|}{ Total } \\
\hline & No. & $\%$ & No. & $\%$ & No. & $\%$ & No. & $\%$ \\
\hline Candida albicans & 98 & 90.74 & 7 & 6.48 & 3 & 2.78 & 108 & 30.51 \\
\hline C. tropicalis & 75 & 93.75 & 2 & 2.5 & 3 & 3.75 & 80 & 22.60 \\
\hline C. parapsilosis & 62 & 79.49 & 13 & 16.67 & 3 & 3.84 & 78 & 22.03 \\
\hline C. krusei & 1 & 100 & - & - & - & - & 1 & 0.28 \\
\hline Trichophyton rubrum & 16 & 50 & 15 & 46.88 & 1 & 3.12 & 32 & 9.04 \\
\hline T. tonsurans & 8 & 88.89 & - & - & 1 & 11.11 & 9 & 2.54 \\
\hline T. mentagrophytes & - & - & 5 & 100 & - & - & 5 & 1.41 \\
\hline Fusarium sp. & 8 & 27.59 & 21 & 72.41 & - & - & 29 & 8.19 \\
\hline Trichosporon sp. & 9 & 90 & 1 & 10 & - & - & 10 & 2.82 \\
\hline Geotrichum candidum & 2 & 100 & 一 & - & - & - & 2 & 0.56 \\
\hline Total & 279 & 78.81 & 64 & 18.08 & 11 & 3.11 & 354 & 100 \\
\hline
\end{tabular}




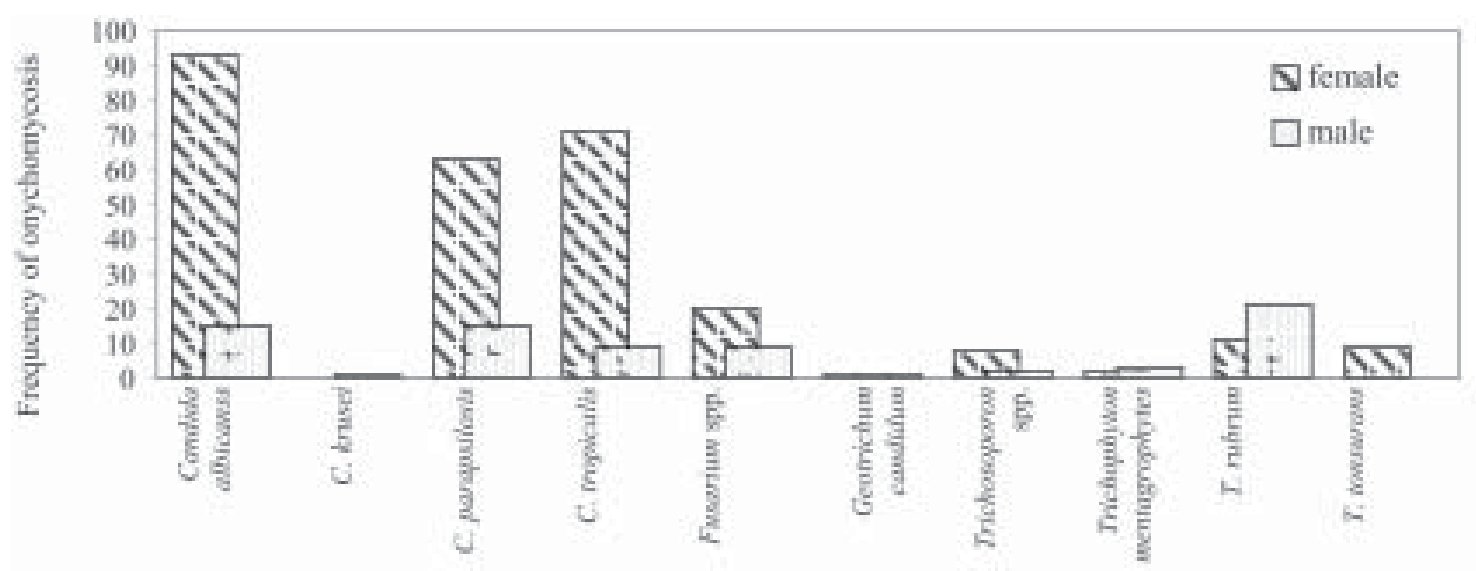

Fig. 3: frequency of onychomycosis to the etiologic agent and the sex.

dren in Rio de Janeiro, Brazil, the presence of Tinea unguim in 3 patients $(2.19 \%)$ was considered very low, such episodes frequently being accompanied by Tinea pedis, not to mention a family history of T. unguim. The low incidence of nail mycosis in infants may be justified by rapid nail growth in children, by the small surface area exposed to fungal invasion and, finally, to the low incidence of $T$. pedis in such individuals (Gupta et al. 1997b).

The female gender was the most frequently infected, encompassing a total of $76 \%$ of patients testing positive for onychomycosis. Such data are in agreement with the findings of several authors (Mercantini et al. 1996, Velez et al. 1997, Bokhari et al. 1999, Lopes et al. 1999, GarciaMartos et al. 2000, Koussidou et al. 2002). The susceptibility of the female gender in our region may be explained by the work habits of such patients who, generally, work performing domestic chores in some occupations, such as: cooks, laundresses, cleaners. Thus, hands remaining wet for most of the day. In addittion, this state of affairs is aggravated by the chemical action of detergents. These causal factors are supported by the large incidence of infection of the nails of women's hands (78.96\%) compared to those of men $(21.04 \%)$, this anatomic site corresponds to $75.2 \%$ of the cases of onychomycosis in our study. Yeasts of the genus Candida were responsible for $70 \%$ of all positive cases, of which, $64.12 \%$ occurred in women.

Dermatophytes correspond to $13 \%$ of the positive cases analyzed. In our study, despite the low positivity of isolation of dermatophytic fungi, the male percentage of onychomycosis of toenails was superior $(\mathrm{p}=0.016)$ to that of females. The use of closed footwear with rubber soles and of synthetic tights, which prevent transpiration may easily justify such findings. The existence of a dominant etiological pattern according to gender has already been demonstrated by Ellabib et al. (2002) and by Pontes et al. (2002). It should be noted that many studies indicate dermatophytes as the main infectious agents in onychomycosis in toenails, the male gender being the most affected (Migdley et al. 1994).

With respect to laboratory diagnosis, direct microscopy examination of clinical specimens was $85.57 \%$. This percentage may be considered high, compared with the work of Kam et al. (1997) and Pontes et al. (2002) who obtained percentages of 14.3 and $68.4 \%$ respectively. Culture was positive in 354 cases, including $44(4.51 \%)$ with negative direct examination and $310(31.76 \%)$ with positive direct examination.

The diagnosis of onychomycosis cannot be performed only clinically, the laboratory studies being extremely important for the purpose of identifying etiological agents involved in the infection (Tasic et al. 2001). The efficiency of the direct examination emphasises the importance of the method, when performed by experienced professionals, favouring the speed of diagnosis and treatment of patients. This approach may be considered, together with culture, as an extremely important procedure for the epidemiological study of onychomycosis.

The yeasts were the etiological agents most widely found in our studied population, with $C$. albicans and $C$. tropicalis being responsible for 30.51 and $22.6 \%$ of all cases evaluated. Species of Candida have been quoted in the literature as being responsible for most cases of onychomycosis world-wide (Kam et al. 1997, Gupta et al. 2000, Dogra et al. 2002, Koussidou et al. 2002).

According to Bokhari et al. (1999) and Lim et al. (1992), the non-dermatophytic filamentous fungus most found in onychomycosis is Fusarium sp., such data being found in our region, where this fungus was the most widespread $(8.19 \%)$ of all non-dermatophytic fungi, being considered only when direct examination and culture were positive three times consecutively.

In conclusion, this study demonstrated that yeasts of the genus Candida were the main agents causing onychomycosis in our region, as well as the importance of performing direct examination and culture in diagnosis of onychomycosis.

\section{REFERENCES}

Bokhari MA, Hussain I, Jahangir M, Haroon TS, Aman S, Khurshid K 1999. Onychomycosis in Lahore, Pakistan. Int J Dermatol 38: 591-595.

De Hoog GS, Guarro J, Gene J, Figueras MJ 2000. Atlas of Clinical Fungi, 2nd ed., Reus: Centraalbureau voor 
Schimmelcultures/Universitat Rovira i Virgili, Spain, 1160 pp.

Dogra S, Kumar B, Bhansali A, Chakrabarty A 2002. Epidemiology of onychomycosis in patients with diabetes mellitus India. Int J Dermatol 41: 647-651.

Drake LA, Dinehart SM, Farmer ER,. Goltz RW, Graham GF, Hordinsky MK, Lewis CW, Pariser DM, Skouge JW, . Webster SB, Whitaker DC, Butler B, Lowery BJ 1996. Guidelines of care for superficial mycotic infections of the skin: onychomycosis. J Am Acad Dermatol 34: 116-121.

Elewski BE 1998. Onychomycosis: pathogenesis, diagnosis and management. Clin Microbiol Rev 11: 415-429.

Elewski BE, Charif MA 1997. Prevalence of onychomycosis: highlights of the third annual international summit on cutaneous antifungal therapy. Clin Infect Dis 23: 305-313.

Ellabib MS, Agaj M, Khalifa Z, Kavanagh K 2002. Yeasts of the genus Candida are the dominant cause of onychomycosis in Libyan women but not men: results of a 2-year surveillance study. Br J Dermatol 146: 1038-1041.

Fernandes NC, Akiti T, Barreiros MGC 2001. Dermatophytoses in children: study of 137 cases. Rev Inst Med Trop São Paulo 43: 83-85.

Garcia-Martos P, Dominguez I, Marin P, Linares M, Mira J, Calap J 2000. Onychomycoses caused by non-dermatophytic filamentous fungi in Cádiz. Enferm Infec Microbiol Clin 18: 319-324.

Ghannoum MA, Hajjeh RA, Scher R, Konnikov N, Gupta AK, Summerbell R, Sullivan S, Daniel R, Krusinski P, Fleckman P, Rich P, Odom R, Aly R, Pariser D, Zaiac M, Rebell G, Lesher J, Gerlach B, Ponce-De-Leon GF, Ghannoum A, Warner J, Isham N, Elewski B 2000. A large-scale North American study of fungal isolates from nails: the frequency of onychomycosis, fungal distribution, and antifungal susceptibility patterns. J Am Acad Dermatol 43: 641-648.

Gupta AK, Jain HC, Lynde CW, Macdonald P, Cooper EA, Summerbell RC 2000. Prevalence and epidemiology of onychomycosis in patients visiting physicians offices: a multicenter Canadian survey of 15,000 patients. J Am Acad Dermatol 43: 244-248.

Gupta AK, Jain HC, Lynde CW, Watteel GN, Summerbell RC 1997a. Prevalence and epidemiology of unsuspected onychomycosis in patients visiting dermatologists' office in Otario, Canada - a multicenter survey of 2001 patients. Int J Dermatol 36: 783-787.

Gupta AK, Sibbald RG, Lynde CW, Hull PR, Prussick R, Shear NH, De Doncker P, Daniel 3rd CR, Elewski BE 1997b. Onychomycosis in children: prevalence and treatment strategies. J Am Acad Dermatol 36: 395-402.
Haneke E 1991. Fungal infections of the nail. Semin Dermatol 10: 41-53.

Kam KM, Au WF, Wong PY, Cheung MM 1997. Onychomychosis in Hong Kong. Int J Dermatol 36: 757-761.

Kiraz M, Yegenoglu Y, Erturan Z, Ang O 1999. The epidemiology of onychomycosis in Istanbul, Tukey. Mycoses 42: 323-329.

Koussidou T, Devliotou-Panagiotidou D, Karakatsanis G, Minas A, Mourellou O, Samara K 2002. Onychomycosis in Northern Greece during 1994-1998. Mycoses 45: 29-37.

Lim JT, Chua HC, Goh CL 1992. Dermatophyte and non-dermatophyte onychomycosis in Singapore. Australas $J$ Dermatol 33: 159-163.

Lopes JO, Alves SH, Mari CR, Oliveira LT, Brum LM, Westphalen JB, Furian FW, Altermann MJ 1999. A tenyear survey of onychomycosis in the central region of the Rio Grande do Sul, Brazil. Rev Inst Med Trop São Paulo 41: 147-149.

Mercantini R, Marsella R, Morretto D 1996. Onychomycosis in Roma, Italy. Mycopathology 1: 25-32.

Migdley G, Moore MK, Cookk, JC, Phan QG 1994. Mycology of nail disorders. J Am Acad Derm 31: 68-74.

Murray SC, Dawber RP 2002. Onychomycosis of toenails: orthopaedic and podiatric considerations. Australas $J$ Dermatol 43: 105-12.

Perea S, Ramos MJ, Garau M, Gonzalez A, Noriega AR, del Palacio A 2000. Prevalence and risk factors of Tinea unguium and Tinea pedis in the general population in Spain. J Clin Microbiol 38: 3226-3230.

Pontes ZB, Lima Ede O, Oliveira NM, Dos Santos JP, Ramos AL, Carvalho MF 2002. Onychomycosis in João Pessoa city, Brazil. Rev Argent Microbiol 34: 95-99.

Sadven P 1990. Laboratory identification and sensitivity testing of yeast isolates. Acta Odontol Scand 48: 27-36.

Tasic S, Stojanovic S, Polijacki M 2001. Etiopathogenesis, clinical picture and diagnosis of onychomycoses. Med Pregl 54: 45-51.

Tosti A, Piraccini BM, Lorenzi S 2000. Onychomycosis caused by non-dermatophytic molds: clinical features and response to treatment of 59 cases. J Am Acad Dermatol 42: 217-224.

Velez A, Linares MJ, Fernandez-Roldan JC, Casal M 1997. Study of onychomycosis in Cordoba, Spain: prevailing fungi and pattern of infection. Mycopathology 137: 1-8.

Weitzman I, Summerbell RC 1996. The dermatophytes. Clin Microbiol Rev 8: 240-259. 
